\title{
Intraperitoneal stone migration during percutaneos nephrolithotomy
}

\author{
Akif Diri $^{1}$, Tolga Karakan ${ }^{1}$, Mustafa Resorlu ${ }^{2}$, Mucahit Kabar ${ }^{1}$, Cankon Germiyanoglu ${ }^{1}$ \\ ${ }^{1}$ Department of Urology, Ankara Training and Research Hospital, Ankara, Turkey; \\ ${ }^{2}$ Department of Radiology, Canakkale Onsekiz Mart University, Faculty of Medicine, Canakkale, Turkey.
}

\begin{abstract}
Summary Percutaneos nephrolithotomy (PNL) is the standard care for renal stones larger than $2 \mathrm{~cm}$. The procedure has some major and minor complications. Renal pelvis laceration and stone migration to the retroperitoneum is one of the rare condition. We report the first case of intraperitoneal stone migration during PNL.
\end{abstract}

KEY WORDS: Complications; Percutaneous nephrolithotomy; Renal pelvis rupture; Renal stone.

Submitted 20 July 2014; Accepted 30 September 2014

\section{INTRODUCTION}

Percutaneos nephrolithotomy (PNL) should be the firstline treatment for large or multi-calyxeal stones (1). PNL is a safe treatment option and associated with low complication rate (2).

The procedure has some major and minor complications like extravasation, renal hemorrhage, colonic injury and pleural injury (3). Clayman et. al. reported extravasation during PNL at a $26 \%$ rate (4). Lee et al. reported $0.9 \%$ renal pelvis laceration, $1 \%$ retroperitoneal stone migration and $0.3 \%$ urinoma in their series (5).

They conservatively treated the migrated stones and urinomas observed in their series. Segura et al reported $0.1 \%$ retroperitoneal stone migration in their series (6). In this study, we report an intraperitoneal stone migration case that occurred during PNL procedure. To our knowledge, after revision of the literature, stone migration to the peritoneum was not previously described.

\section{Case report}

A 38 years female patient presented with right renal colic at a different center. Urogenital system examination revealed only right costovertebral sensitivity.

The patient had previously two pyelolithotomy operations. Radiological examination showed a $3 \mathrm{~cm}$ right renal pelvis stone (Figure 1) and PNL was performed. During the procedure pelvic rupture occurred with stone migration into the peritoneum. The procedure was terminated with placing a re-entry catheter. At postopera- tive first day, the patient showed abdominal distension due to free fluid in the abdomen. Vital signs and biochemical examinations of the patient were normal. The patient was followed closely and at the end of the seventh day the urinary tract was checked with antegrade pyelography that showed no extravasation and that the collecting system was intact.

The re-entry catheter was removed and the patient was discharged and referred to our clinic. At plain radiograph there was a $2 \mathrm{~cm}$ stone at the level of the pelvic bone (Figure 2).

CT scan demonstrated that the stone was posterior to the bladder on the right side. We planned laparoscopic exploration but intraoperatively we found many adhesions and we had to switch to open surgery.

The stone was found in the vesicouterine pouch and extracted (Figure 3). After the operation the patient was discharged without complicationa at the fourth postoperative day.

\section{Figure 1.}

Plain radiograph of the renal stone before PNL operation.

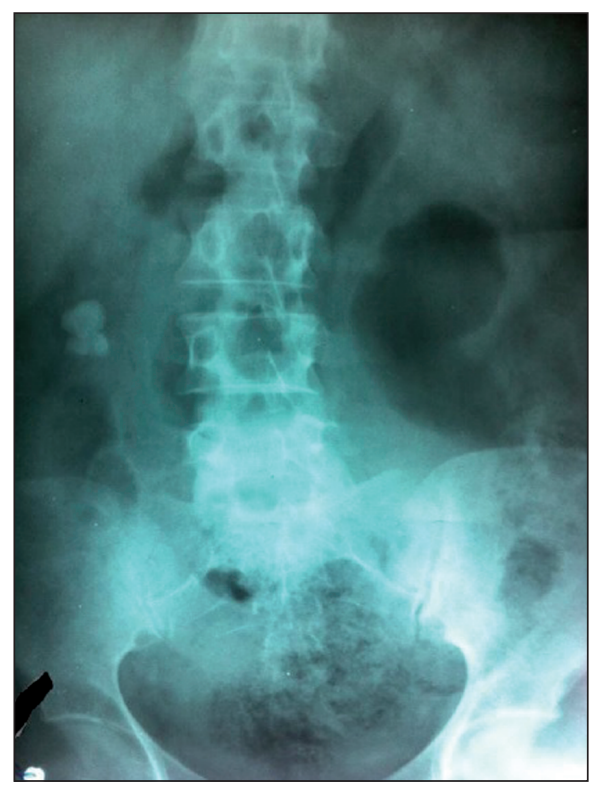




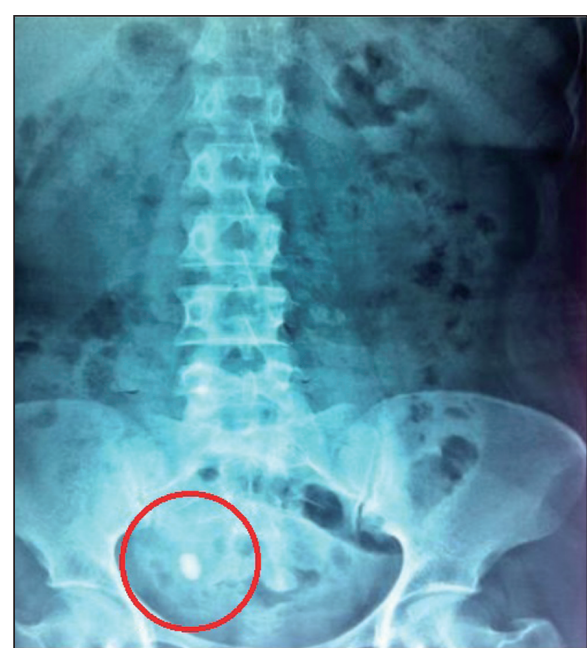

Figure 2.

Plain

radiograph

of the

migrated

stone.

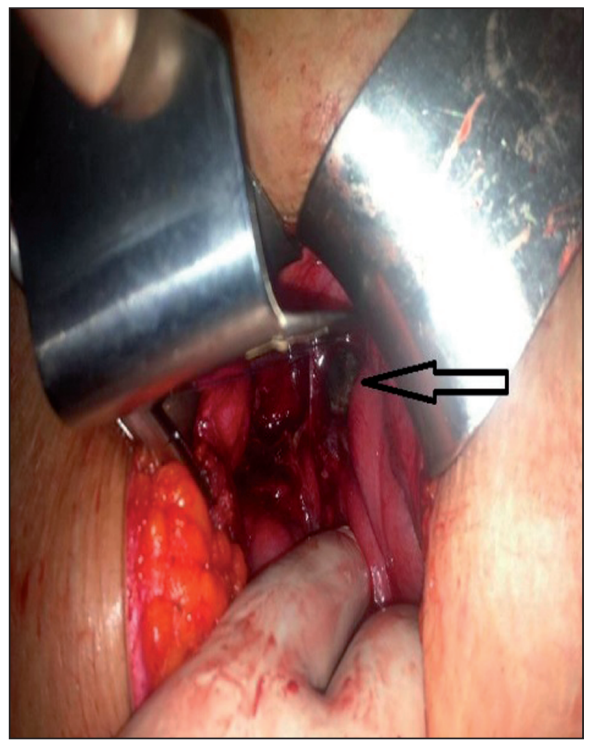

Figure 3

Intraoperative

stone

extraction.

The stone is

located in the vesicouterine pouch.

\section{Discussion}

The most common complications of PNL are extravasation (7.2\%), transfusion (11.2-17.5\%) and fever (21$32.1 \%)(3)$

Lacerations may occur during dilatation or manipulation with nephroscope and during lithotripsy. Fluoroscopic monitoring during dilatation and gentle manipulations may reduce the risk of collecting system injury. The inflow and outflow of the irrigation fluid must be measured. If there is a inequality that exceeds $500 \mathrm{ml}$, the procedure must be stopped and a nephrostomy must be placed (3).

Stone migration in the peritoneum is a rare condition. Especially for operated kidneys PNL can be a complicated proedure and collecting system perforation with stone migration may occur like in the presented case.

\section{REFERENCES}

1. Lingeman JE, Newmark JR, Wong MYC: Classification and management of staghorn calculi. In: Smith AD (editor) Controversies in endourology. Saunders, Philadelphia 1995, pp. 136-44.

2. Rudnick DM, Stoller ML. Complications of percutaneous nephrostolithotomy. Can J Urol. 1999; 6:872-5.

3. Michel MS, Trojan L, Rassweiler JJ. Complications in percutaneous nephrolithotomy. Eur Urol. 2007; 51:899-906.

4. Wolf JS Jr, Clayman RV. Percutaneous nephrostolithotomy: What is its role in 1997?. Urol Clin North Am. 1997; 24:43-58.

5. Lee WJ, Smith AD, Cubelli V, et al. Complications of percutaneous nephrolithotomy. AJR Am J Roentgenol. 1987; 148:177-80.

6. Segura JW, Preminger GM, Assimos DG, et al. Nephrolithiasis Clinical Guidelines Panel summary report on the management of staghorn calculi. The American Urological Association Nephrolithiasis Clinical Guidelines Panel. J Urol. 1994; 151: 1648-51.

\section{Correspondence}

Akif Diri, MD

Tolga Karakan, MD

Mucahit Kabar, MD

Cankon Germiyanoglu, MD

Department of Urology, Ankara Training and Research Hospital

Ankara, Turkey

Mustafa Resorlu,MD (Corresponding Author)

mustafaresorlu77@gmail.com

Department of Radiology,Faculty of Medicine,

Canakkale Onsekiz Mart Universitesi, Terzioglu Yerleskesi,

Barbaros Mh, 17100, Canakkale, Turkey 